\title{
Educação financeira: projeto Mulungú de fomento à economia doméstica em uma comunidade do Jacintinho
}

\author{
Financial education: Mulungu project to promote domestic \\ economy in a Jacintinho community \\ Educación financiera: proyecto Mulungú para promover la economía \\ doméstica en una comunidad de Jacintinho
}

RERISSON KAIQUE VALENTIM

Orcid ld: http://orcid.org/0000-0002-5415-9813

Universidade Federal de Alagoas

KELLY CHRISTIAN RODRIGUES

Orcid Id: http://orcid.org/0000-0003-1185-8398

Universidade Federal de Alagoas

NATALLYA LEVINO

Orcid Id: http://orcid.org/0000-0002-1215-3798

Universidade Federal de Alagoas

\begin{abstract}
Resumo: O objetivo deste artigo é analisar o processo de introdução da educação financeira na vida de estudantes do EJA (Educação Jovens e Adultos) de uma escola pública na cidade de Maceió/AL. Foi realizada uma pesquisa descritiva exploratória, através da aplicação de questionários, durante os meses de junho a setembro de 2019. Os dados mostraram que os estudantes apresentavam comportamento de inadimplência e desconhecimento das ferramentas de controle financeiro. Conclui-se que o projeto de extensão universitária foi relevante por levar informações de forma facilitada e lúdica aos estudantes.
\end{abstract}

Palavras-chave: Economia Doméstica; Finanças Pessoais; Educação de Jovens e Adultos; Extensão Universitária.

\begin{abstract}
The aim of this article is to analyze the process of introducing financial education into the lives of EJA (Youth and Adult Education) students at a public school in the city of Maceio / AL. An exploratory descriptive research was carried out, through the application of questionnaires, during the months of June to September 2019. The data showed that the students presented default behavior and lack of knowledge of the financial control tools. It is concluded that the university extension project was relevant for bringing information in an easy and entertaining way to students.
\end{abstract}

Keywords: Home Economics; Personal finances; Youth and Adult Education; University Extension. 
Resumen: El propósito de este artículo es analizar el proceso de introducción de la educación financiera en la vida de los estudiantes de EJA (Educación de Jóvenes y Adultos) en una escuela pública en la ciudad de Maceió/Al. Se realizó una investigación descriptiva exploratoria, mediante la aplicación de cuestionarios, de junio a septiembre de 2019. Los datos mostraron que los estudiantes presentaron un comportamiento de incumplimiento y falta de conocimiento de las herramientas de control financiero. Se concluye que el proyecto extensión universitaria fue relevante para brindar información de una manera fácily entretenida a los estudiantes.

Palabras clave: Economía Doméstica; Finanzas Personales; Educación de Jóvenes y Adultos; Educación Universitaria.

\section{INTRODUÇÃO}

A gestão financeira pessoal tem como base a formulação de estratégias para administrar, manter ou acumular bens e valores que compõem o patrimônio individual e/ou familiar. A estratégia pode ser elaborada a curto, médio ou longo prazos, mantendo a estabilidade econômico-financeira nos casos tanto individual como familiar. Porém, se faz necessário ter um mínimo de conhecimento em educação financeira para que tais medidas possam ser tomadas.

Para Macedo (2016), as pessoas não tiveram o aprendizado mínimo de finanças, não aprenderam a lidar com dinheiro em seu cotidiano e se endividam querendo comprar mais do que realmente conseguem arcar com as suas receitas e, com um acesso maior ao crédito atrelado a um consumo excessivo, essa situação tende a piorar (LIMA, 2016). Em comunidades carentes isso se torna crucial, pois uma melhor gestão financeira faz com que existam menores perdas financeiras.

Quando se discute Economia Doméstica vale evidenciar que não é apenas um conjunto de conhecimentos de ordem prática, os quais as donas de casa devem possuir para conseguir executar as tarefas caseiras, é importante salientar também a necessidade do conhecimento científico e profissional no assunto, para as escolas, famílias e toda a sociedade. Estudar os elementos de Economia Doméstica é de grande importância porque os fenômenos que se verificam na sociedade são muito complexos e, para que ocorra uma solução adequada, é preciso conhecer noções científicas especializadas (OLIVEIRA, 2006).

Silva e Bezerra (2016) citam um estudo de D’Aquino (2008), o qual mostra que as famílias acabam não dando a importância que se faz necessária aos pequenos gastos, incidindo em um descontrole do orçamento doméstico. O que essas pessoas acabam não avaliando é que essas pequenas compras podem vir a gerar dívidas, fazendo-se então necessária uma mudança de hábito e de algum tipo de estudo para aquisição de conhecimentos, podendo no futuro conseguir o sonhado equilíbrio financeiro. 
Os autores também mostram uma realidade que acaba ocorrendo nos espaços escolares brasileiros, a falta de debate sobre planejamento doméstico, mostrando a necessidade de educar crianças e jovens com conceitos básicos baseados na educação financeira e economia doméstica, fazendo isso de uma forma que possa envolver os familiares para se tenha um maior aproveitamento (SILVA; BEZERRA, 2016).

Para Silva e Powell (2013) quando se fala em educação financeira no âmbito escolar o objetivo é de estimular os alunos a conhecerem temas ligados ao gerenciamento financeiro na esfera individual, doméstica e da coletividade, levando-os a refletirem e realizarem suas escolhas financeiras com convicção. $\mathrm{O}$ que pode possibilitar às pessoas a alcançarem a vida adulta tomando decisões financeiras com mais responsabilidade e assertividade.

Quando a sociedade se omite em debater o conhecimento em finanças, economia e impostos acaba gerando adultos sem instrução financeira e sem habilidades necessárias para o melhor controle do dinheiro, isso pode tornar o problema mais grave, pois nenhuma profissão está livre de ter algum tipo de problema que envolva dinheiro ou impostos (SILVA; BEZERRA, 2016).

Com isso, os autores mostram a necessidade de desenvolver projetos com alunos do Ensino Fundamental sobre orçamento familiar, dentro das atividades da disciplina de Matemática. Isso se faz necessário devido à ausência deste tipo de conteúdo programático na disciplina, pois a inserção desse tipo de conteúdo despertará nos jovens um interesse maior, o que acabará facilitando a aprendizagem. Entretanto, alguns fatores (econômicos, culturais, educacionais, etc.) podem refletir no desinteresse diante desse tema.

Vieira, Bataglia e Sereia (2011) creditam ao passado cultural e histórico do país que as características marcantes da economia eram as variações monetárias e as altas taxas de inflação. Antes do plano real, a economia brasileira era bastante instável, fazendo com que uma geração vivenciasse uma cultura herdada pela hiperinflação ocorrida nas décadas de 80 e 90 , na qual, toda tentativa de planejamento a médio ou longo prazos seria desalentadora (MACEDO, 2016; OLIVEIRA et al., 2014).

Em Alagoas, objeto do estudo, Carvalho (2016) evidencia como um estado com bastantes desafios, considerados graves, porém a superar. Uma sociedade pobre como a alagoana precisa interromper o "fator intergeracional da pobreza", que é a miséria passada de pais para filhos, da qual nenhum membro consegue sair das condições de penúria e ignorância. É preciso ações públicas e programas articulados, como: transferência de renda, educação, saúde, para 
que se possam garantir condições de vida digna para a maioria da população, incorporando-a assim no processo de produção e consumo. Mostrando, então, que a educação financeira da população pode auxiliar na transformação social.

A capacidade de saber resolver questões financeiras é muito importante para o desenvolvimento educacional, como as demais disciplinas já ministradas durante todo o período escolar, mas essa matéria não faz parte do currículo escolar; apenas em 2020 quando todas as escolas do país se adequarem à Base Nacional Comum Curricular (BNCC) essa disciplina começará a ser ofertada a todos os alunos do ensino fundamental do país.

Dado esse cenário, em 2018 foi submetido a um edital de extensão universitária o "Projeto Mulungu de Fomento à Economia Doméstica em uma comunidade no bairro do Jacitinho/AL". O bairro foi escolhido por ser uma região considerada popular, com diversidade de comércio local, entretanto de baixo poder aquisitivo da população e com alto índice de criminalidade. Tais fatores tendem a refletir no nível de conhecimento associado à educação e, especificamente, na educação financeira dos moradores (SILVA, 2014; GOVERNO DE ALAGOAS, 2019).

Visto isso, o objetivo deste artigo é analisar o processo de introdução da educação financeira na vida de estudantes do EJA (Educação Jovens e Adultos) de uma escola pública na cidade de Maceió/AL. Ratifica-se a importância em abordar e exemplificar com métodos práticos do cotidiano destes estudantes e apresentar sua evolução durante o tempo em que foram ministradas as oficinas de educação financeira.

Vários outros estudos recentes têm demonstrado a relevância de projetos de educação financeira para a comunidade (TEIXEIRA, 2015; BRUTES; SEIBERT, 2014; QUINTANA; PACHECO, 2018), mostrando que o tema ainda carece de maiores análises, principalmente, em comunidades como as analisadas neste presente estudo.

Este trabalho está dividido em mais quatro tópicos além desta introdução. São eles fundamentação teórica, metodologia, análise dos dados obtidos por meio da pesquisa realizada, análise dos resultados e a conclusão final do estudo.

\section{FUNDAMENTAÇÃO TEÓRICA}

Para se ter um controle sobre as dívidas tanto a pessoa jurídica, quanto a pessoa física necessitam elaborar um planejamento financeiro. Gitman (2004) mostra que esse tipo de plano auxilia na orientação para a direção que se deve 
seguir, sendo a coordenação e controle sobre as providências que precisam ser tomadas para conseguir atingir-se determinado objetivo. Estes podem auxiliar a gestão financeira, reduzir riscos e evitar o endividamento.

$\mathrm{O}$ endividamento pode ser descrito como um débito que pode ser oriundo de uma dívida ou de várias dívidas (RIBEIRO et al., 2009). Santos e Silva (2014) destacam que, no mundo atual, verificou-se um aumento expressivo no endividamento familiar e que o mau ou não gerenciamento das finanças familiares/pessoais está entre as principais causas desse endividamento e pode-se justificar esse fato à falta de planejamento orçamentário e não acompanhamento do objetivo da utilização das suas finanças.

De acordo com dados da Pesquisa de Endividamento e Inadimplência do Consumidor (PEIC, outubro/2019), 65,1\% das famílias maceioenses estão endividadas. Esse dado mostra que menos da metade das pessoas fazem alguma programação e planejamento financeiro para tentar enfrentar períodos em que dificuldades econômicas possam surgir.

Observando os dados desta pesquisa é possível perceber que a principal dívida registrada advém do cartão de crédito, principalmente de pessoas que recebem mais de 10 salários mínimos, tendo uma diferença de apenas 8,2\% em relação ao percentual dos endividados que recebem até 10 salários. A Tabela 01 apresenta os principais tipos de dívidas presentes nos residentes de Maceió/Al.

\section{Tabela 01 - Tipo de dívida - Maceió}

\begin{tabular}{|c|c|c|c|}
\hline Tipo de dívida & Total (\%) & Até 10 s.m. (\%) & Mais de 10 s.m. (\%) \\
\hline Cartão de crédito & 84.5 & 84 & 92.2 \\
\hline Cheque especial & - & - & - \\
\hline Cheque Pré-datado & 0.2 & 0.2 & - \\
\hline Crédito consignado & 2.2 & 2.3 & - \\
\hline Crédito pessoal & 6.3 & 6.6 & 2 \\
\hline Carnês & 12.2 & 12.4 & 9.8 \\
\hline Financiamento de carro & 0.2 & 0.2 & - \\
\hline Financiamento de casa & 3.2 & 2.8 & 9.8 \\
\hline Outras dívidas & 7.4 & 7.9 & - \\
\hline Não sabe/Não respondeu & 0.3 & 0.3 & - \\
\hline
\end{tabular}

Fonte: PEIC/outubro 2019.

A PEIC outubro/2019 também mostra que aproximadamente $28.4 \%$ das famílias maceioenses que estão inadimplentes estão com as dívidas em atraso e ainda que $64.3 \%$ destas famílias relatam que não terão condições de pagar essa dívida no próximo mês. Apenas 3.3\% afirmam que conseguirão pagar as dívidas 
atrasadas nesse prazo. A média de atraso dessas contas é de 78.5 dias. Tais dados corroboram a necessidade e a carência existente de instrumentos de educação financeira e economia doméstica junto à sociedade.

\section{EDUCAÇÃO FINANCEIRA E A FAMÍLIA}

Vieira; Batlaglia; Sereia (2011) trazem uma definição de Educação Financeira feita pela Organização de Cooperação e de Desenvolvimento Econômico - OCDE (2005), como o processo no qual consumidores e investidores passam a aprimorar o seu conhecimento a respeito dos conceitos e dos produtos financeiros e que, através da informação, instrução e/ou conselhos objetivos, passam a desenvolver habilidades e confiança para conhecer melhor os riscos e as oportunidades financeiras.

Para a OCDE (2005), a educação financeira pode beneficiar a todos, seja qual for o nível de renda. Para aqueles que estão entrando no mercado de trabalho, ela pode ser uma ferramenta básica de planejamento e poupança, para que suas despesas e dívidas permaneçam controladas; pode ajudar às famílias a poupar, dando a oportunidade de melhores condições para custear a educação de seus filhos, ter plano de saúde e tornar a vida mais cômoda.

O grupo de aposentados ou próximo dessa aposentadoria podem se beneficiar com uma poupança boa o suficiente para não trabalhar e obter habilidades necessárias para investir, garantindo conforto e segurança (VIEIRA; BATAGLIA; SEREIA, 2011). Vale ressaltar que alguns destes grupos vivenciaram períodos recentes de mudanças de planos econômicos que pode ter refletido nas suas preferências financeiras.

Conforme Picinni e Pinzetta (2014) apud D’Aquino (2008, p. 9), umas das "consequências herdadas pelo período de inflação foi a ausência de uma educação financeira sólida em nossa formação. E, como não aprendemos, precisamos agora nos esforçar em dobro para ensiná-la a nossos filhos".

Assim, quanto mais cedo as pessoas tiverem contato com a educação financeira, melhores serão os resultados na renda familiar. Uma sociedade educada financeiramente torna-se mais responsável pelos seus gastos e receitas, compreendendo a importância do dinheiro e como a sua gestão é indispensável no cotidiano. 


\section{ECONOMIA DOMÉSTICA}

Uma das vertentes da Educação Financeira é a Economia Doméstica que, segundo Oliveira (2006), passou a existir em 1909 por conta de mudanças sociais que tiveram lugar com a origem da revolução industrial. Este tipo de conhecimento era referente às funções da família e buscava a eficácia científica em cada tarefa cotidiana da casa, gerando assim melhoria da qualidade de vida das famílias. Essa vertente lida com conhecimentos científicos teórico-práticos que se relaciona à esfera reprodutiva, na qual, se dá a reprodução social dos seres humanos, que tem como base a socialização, cuidados com higiene, saúde, habitação e alimentação.

A autora traz, ainda, informações de diversas reuniões que duraram de 1925 até 1935, em que diversas pessoas de vários campos educacionais envolveramse em conferências que visavam discutir a criação de uma nova profissão, a qual chamavam Home Economics - Economia Doméstica. Os conferencistas acreditavam que a Economia Doméstica tinha um importante papel na sociedade e, segundo eles, a profissão poderia ajudar lares e famílias a desenvolver a ética e tornar o ser humano livre, afinal são participantes conscientes da melhoria da sociedade.

Em 1933 teve início o que levou a Economia Doméstica a outro patamar que se estendeu às escolas profissionais secundárias femininas com o intuito da formação das "futuras donas-de-casa". Atualmente, o conceito se expandiu e continua presente em vários segmentos da sociedade. Para Amaral Junior (2013), o estudo da economia doméstica precisa se adaptar às novas demandas da sociedade, porém o campo de pesquisa é crescente.

Vários estudos têm sido desenvolvidos para mostrar os diversos impactos da economia doméstica em cenários distintos. Um estudo com objetivo de conhecer as causas da desorganização financeira entre as famílias residentes em um loteamento na cidade Paulista em Pernambuco trouxe um pouco da realidade de pessoas cuja administração dos recursos não é das melhores.

Para Mendonça e Melo (2009), as famílias de diferentes rendas acabam tendo comportamentos diferentes no que diz respeito à questão da busca, da aquisição, do consumo e dos recursos, porém a má administração é decorrente de como os rendimentos e despesas reagem a restrição orçamentária, afetando diretamente a qualidade de vida das famílias, mostrando a importância da economia familiar e do orçamento doméstico.

O tema não se restringe apenas ao universo familiar, em outra pesquisa realizada por Vieira; Bataglia; Sereia (2011) nessa área, mas com alunos de uma universidade pública no Paraná, mostrou-se uma perspectiva de estudantes da graduação, como eles lidam com o tema economia doméstica, concluindo através 
das hipóteses elaborada pelos autores, que os alunos dos cursos de Administração, Ciências Econômicas e Ciências Contábeis das séries finais apresentaram um nível de acerto das questões propostas superior aos alunos das séries iniciais, porém houve questões em que os alunos das primeiras séries tiveram maior número de acertos que os da última série.

Para os autores a formação acadêmica contribui para a melhor tomada de decisões de consumo, investimento e poupança dos indivíduos, porém há outras fontes de conhecimento que são também relevantes, como a experiência prática e essas discussões no ambiente familiar.

Estimular a discussão dos conceitos da economia doméstica, seja no ambiente escolar e/ou no familiar, pode auxiliar na construção de uma sociedade mais responsável financeiramente, evitando comportamento de desequilíbrio financeiro e estimulando a boas práticas na gestão do dinheiro.

\section{PROCEDIMENTOS METODOLÓGICOS}

O Projeto Mulungú de extensão universitária foi desenvolvido com o objetivo de levar conhecimentos de educação financeira e economia doméstica para as famílias que residem no bairro do Jacintinho em Maceió/Al. Para isso, buscou-se utilizar oficinas com temas práticos, utilizando recursos visuais (slides e estudos de casos) e algumas dinâmicas.

O cronograma do projeto previa as seguintes etapas: Estudo dos conceitos de economia doméstica e educação financeira ( 2 meses); Análise de projetos semelhantes (2 meses); Comparação de metodologias (1 mês); Desenvolvimento de conteúdo das oficinas (2 meses); Aplicação das oficinas (4 meses); e Análise do projeto (1 mês).

O local escolhido para ministrar as oficinas foi a Escola Estadual Theonilo Gama, localizada na rua principal do bairro, com as turmas do $4^{\circ}$ ano da modalidade de ensino Educação de Jovens e Adultos (EJA), pois considerouse que os alunos do último ano já teriam noções básicas de matemática geral e alguma familiaridade com matemática financeira, além de acreditar-se que por se tratar de uma turma de jovens e adultos alguns já teriam obrigações financeiras com a família e/ou individualmente, fazendo assim com que o interesse pelo tema fosse maior.

Para a elaboração do material empregado nas oficinas foram analisadas outras metodologias adotadas em trabalhos semelhantes, anteriormente desenvolvidos (MACÊDO, 2016; OLIVEIRA et al, 2014), para que fosse desenvolvido o seu próprio escopo com base no público-alvo. 
Os temas das oficinas estavam todos voltados à economia doméstica e foram trabalhados numa linguagem clara e compreensível ao público-alvo. Assim, foi definido que seriam realizadas quatro oficinas, uma por mês. A periodicidade foi definida junto com a coordenação acadêmica da escola, para que não fosse comprometido o conteúdo escolar previsto.

Foram definidas, antecipadamente, as seguintes temáticas: 1. Qual é seu sonho? (apresentação do projeto e dos temas centrais); 2. Matemática no cotidiano (juros); 3. Planejamento financeiro; e 4. Gestão de custos pessoais. As oficinas aconteciam na sede do colégio, às quartas ou quintas-feiras, com duração de 2 horas e 30 minutos (média).

As oficinas ocorreram entre os meses junho de 2019 a setembro de 2019. Foi elaborado um livro sobre educação financeira que balizou os temas das oficinas acima citadas; cada tema trazia aspectos da educação financeira e como eles poderiam lidar em diversas situações que envolvia dinheiro, sendo cada oficina complementada com a oficina seguinte com aspectos cotidianos.

Para conhecer o perfil dos participantes, foi desenvolvido um questionário com 30 perguntas que foi aplicado antes da primeira oficina prática com 50 alunos. Utilizou-se a plataforma Google forms que é uma ferramenta online, para coleta e tabulação dos dados.

O questionário buscou identificar as principais características dos participantes, o nível de conhecimento e saúde financeira. Com a análise do questionário foram realizados alguns ajustes nas oficinas de modo a torná-las mais atrativas para o público presente e suas necessidades.

O questionário foi elaborado com base em diversos estudos já citados ao longo do trabalho, sendo esse respaldado pelo Comitê de Ética em Pesquisa (CEP) da Universidade Federal de Alagoas (UFAL), aprovado com o CAAE 02847218.8.0000.5013 para garantir a segurança e integridade dos entrevistados.

No decorrer das oficinas sentiu-se a necessidade de desenvolver um novo questionário - aplicado a 41 alunos - no mesmo local e mesmo público, com o objetivo de detectar o que de importante ficou como aprendizado.

O questionário era composto de três perguntas fechadas e uma aberta e foi aplicado em setembro, após o final da última oficina. Por haver alunos faltosos na última oficina acabou não atingindo o mesmo quantitativo de respondentes que o primeiro questionário.

Para analisar e fazer a inferência dos dados coletados foi utilizada a estatística descritiva, a qual é trazida por Guedes et al. (2005) como objetivo básico para sintetizar uma série de valores de mesma natureza, permitindo então que o pesquisador tenha uma visão global da variação que possa ocorrer. Por 
meio desses métodos, o pesquisador consegue fazer uma análise clara e objetiva dos dados coletados, podendo visualizar as respostas e tirar conclusões acerca do assunto estudado.

\section{RESULTADOS E DISCUSSÕES}

Este tópico apresenta os principais resultados obtidos pela aplicação dos questionários e sua análise.

\section{PERFIL DOS ENTREVISTADOS}

Dos 50 alunos entrevistados, mostrou-se que era um grupo composto por $52 \%$ de mulheres, $46 \%$ de homens e $2 \%$ não se identificaram, em que a grande maioria (84\%) declarou morar na parte do bairro denominada Jacintinho, tendo o restante residente na Grota do Cigano (4\%), Piabas (4\%) e 8\% fora da delimitação do bairro. Deste total de estudantes, 48\% vivem de aluguel; 38\% têm casa própria, e destes, $4 \%$ estão ainda em processo de quitação; $6 \%$ moram em uma casa cedida por algum parente; e $2 \%$ optou por não responder.

No que diz respeito à situação de moradia dos respondentes, a maioria mora em casa alugada (48\%), seguidos por casa própria/quitada (34\%), já os que moram em casa cedida ou emprestada representam $12 \%$ e apenas $4 \%$ dos respondentes ainda estão pagando o financiamento da sua moradia e $2 \%$ não responderam, como pode ser visto na tabela 2.

Ao compararmos as respostas obtidas, podemos perceber que há uma diferença dos dados nacionais já que, conforme a Pesquisa Nacional por Amostra de Domicílios - PNAD realizada pelo IBGE (Instituto Brasileiro de Geografia e Estatística) em 2015, a maioria da população tem moradia própria, representando $74,8 \%$ do total, seguido de moradia alugada, $17,9 \%$ e $7,1 \%$ residem em moradia cedida. A tabela 03 apresenta o status de moradia dos entrevistados. 
Tabela 02 - Situação da moradia atual dos participantes

\begin{tabular}{|c|c|c|}
\hline Possibilidades & Frequência & Porcentagem \\
\hline Alugada & 24 & 48,0 \\
\hline Cedida/emprestada & 06 & 12,0 \\
\hline Própria e quitada & 17 & 34,0 \\
\hline Própria em financiamento & 02 & 4,0 \\
\hline Não quis responder & 01 & 2,0 \\
\hline Total & 50 & 100,0 \\
\hline
\end{tabular}

Fonte: Elaborada pelos autores.

A respeito do estado civil dos respondentes, $74 \%$ declararam que estão solteiros; $22 \%$ casados ou em união estável; $2 \%$ declararam que estão divorciados; e outros $2 \%$ viúvos. Do total de entrevistas $60 \%$ responderam não terem filhos e os outros $40 \%$ têm. Desses entrevistados: $50 \%$ têm dois filhos; $35 \%$ têm três ou mais; e $15 \%$, somente um filho.

Quando perguntados a respeito da profissão que exercem no momento da pesquisa, 38\% declarou não estar trabalhando no momento; e 10\% optaram por não responder. Os $52 \%$ que trabalham estão divididos em vários cargos, sendo as mais comuns as profissões de: pintor, vendedor, autônomo e serviços ligados à casa, como por exemplo, doméstica, diarista e cozinheira.

A maioria deles (40\%) vive em uma casa com quatro ou mais pessoas; $26 \%$, com três; $24 \%$, com mais uma pessoa; $8 \%$ vivem sozinhos; e $2 \%$ optaram por não responder. Depois de saber o quantitativo de pessoas por residência, foi perguntado quantas pessoas na casa têm algum trabalho remunerado, 34\% respondeu ter duas pessoas em casa com trabalho; $48 \%$, apenas uma pessoa; $8 \%$ com três pessoas; e 10\% dos respondentes encontram-se com todos os familiares desempregados.

Após esse levantamento, foi questionado se todas as pessoas que trabalham e moram com eles, incluindo os entrevistados, trabalham de carteira assinada. Foi coletado que $60 \%$ não têm todos os residentes com carteira assinada, contra $40 \%$ que têm todos os moradores com trabalho regulamentado.

\section{RENDA}

De acordo com os dados encontrados, $58 \%$ teê uma renda entre um e dois salários mínimos; $12 \%$ com renda total entre dois e três salários; $6 \%$ com mais de três salários; $14 \%$ não chega nem a um salário mínimo completo; e 10\% optaram por não informar este quesito. Segundo Mattoso e Rocha (2005), a escassez ou 
limitação de recursos pode agravar a vulnerabilidade dos consumidores de baixa renda, pois imprevistos podem acontecer e gerar um desequilíbrio no orçamento das famílias.

Como uma forma de atenuar esse desequilíbrio dos brasileiros mais pobres, o governo repassa uma quantia em dinheiro através do programa Bolsa família. Entre os entrevistados: 28\% recebem esse subsídio governamental, 50\% deixaram de receber, e $22 \%$ nunca receberam ajuda financeira desse tipo. Em Alagoas, em setembro de 2019, o programa atendeu 394.847 famílias e distribuiu o total de $\mathrm{R} \$ 76.830 .145,00$ por todo o estado. Se analisar apenas Maceió foram beneficiadas cerca de 56 mil famílias (MINISTÉRIO DA CIDADANIA, 2019). A tabela 3 relata essas informações.

\section{Tabela 03 - Renda total de cada residência}

\begin{tabular}{|c|c|c|}
\hline Possibilidades & Frequência & Porcentagem \\
\hline Menos que um salário mínimo & 07 & 14,0 \\
\hline 1 salário mínimo ( $\mathrm{R} \$ 954)$ a 2 salários $(\mathrm{R} \$ 1.908)$ & 29 & 58,0 \\
\hline 2 salários mínimos ( $\mathrm{R} \$ 1.908$ ) a 3 salários ( $\mathrm{R} \$ 2.862)$ & 06 & 12,0 \\
\hline Mais de 3 salários (Mais de $\mathrm{R} \$ 2.862)$ & 03 & 6,0 \\
\hline Prefiro não dizer & 05 & 10,0 \\
\hline Total & 50 & 100,0 \\
\hline
\end{tabular}

Fonte: Elaborada pelos autores.

Em Alagoas como um todo, a PNAD/2015 revela que 53\% das pessoas acima de 15 anos são economicamente ativas e que $27,34 \%$ da população recebe entre 1 e 2 salários mínimos; 5,14\% recebem entre 2 e 3 salários mínimos. Já os que recebem até 1 salário mínimo representam 44,63\% do total. Percebe-se aqui que os dados do estado de Alagoas se assemelham aos dados coletados dos alunos do EJA.

\section{PERFIL CONSUMIDOR}

Para identificar o perfil de consumo, constatou-se que 30,6\% estão consumindo toda a sua renda, sem se preocupar com o longo prazo. Enquanto que $24,5 \%$ dos entrevistados demonstram preocupação, porém não possuem recursos excedentes. E os 14,3\% dos entrevistados estão trabalhando para ajudar seus familiares, outros $12,2 \%$ encontram-se endividados sem saber como irão financiar a dívida. Outros 10,2\% encontram-se com dívida igual os citados anteriormente, porém estão buscando formas de liquidar suas dívidas. Do total 
de respostas, $12,2 \%$ estão pensando no futuro, entre eles: 6,1\% querem comprar algo que sonham, outros $6,1 \%$ estão colocando o excedente na poupança para terem uma garantia.

De acordo com Nogami; Vieira e Medeiros, (2012); Hemais, Casotti e Rocha, (2013), os consumidores de baixa renda têm necessidade de aceitação social via consumo; tal comportamento contribui para o endividamento e pode evoluir para gerar mazelas sociais. A tabela 4 apresenta a situação financeira atual dos entrevistados.

\section{Tabela 04 - Situação financeira atual}

\begin{tabular}{|c|c|c|}
\hline Possibilidades & Frequência & Porcentagem \\
\hline Juntando dinheiro para pagar uma dívida & 05 & 10,2 \\
\hline Com dívidas e sem saber como pagar & 06 & 12,2 \\
\hline Guardando dinheiro para comprar algo que quer muito & 03 & 6,1 \\
\hline Vivendo e gastando & 15 & 30,6 \\
\hline Fazendo uma poupança para o futuro & 03 & 6,1 \\
\hline Trabalhando para ajudar sua família & 07 & 14,3 \\
\hline Preocupado porque o dinheiro não sobra & 12 & 24,5 \\
\hline Total & 51 & 100 \\
\hline
\end{tabular}

Fonte: Elaborada pelos autores.

Foi observado anteriormente que uma parte dos entrevistados está endividada ou somente gastando. Nesse caso, para então saber se eles são compradores impulsivos foram apresentadas algumas situações cotidianas para observar este tipo de comportamento. A maior parte deles (34\%) responderam prontamente que nunca compraram nada impulsivamente, já $24 \%$ relataram que acabaram precisando do dinheiro e gastaram com outra coisa mais importante, enquanto $14 \%$ mostraram-se arrependidos, pois perceberam que não precisavam tanto do produto. Outros 10\% dos entrevistados acabaram encontrando o mesmo produto adquirido por um preço bem mais em conta, já outros $10 \%$ não tiveram a satisfação desejada e $6 \%$ se arrependeram devido à péssima qualidade do produto.

Para Nardi (2009), a recente expansão do crédito e o crescimento da bancarização resultaram em uma imensa demanda reprimida por anos de estagnação econômica e crises inflacionárias. Assim, esse público pôde fazer aquisições que anteriormente eram inviáveis, isso contribuiu para o estímulo ao consumo. 
O que pode ser observado é que enquanto $34 \%$ não são impulsivos na hora de adquirir algum produto, 64\% precisavam aprender a pesquisar melhor os produtos antes de efetivar a compra, analisar se realmente estão precisando do produto naquele momento e, por fim, verificar se o dinheiro que irão gastar poderá fazer falta em alguma necessidade futura.

De acordo com uma pesquisa do SPC Brasil (2016) mostra-se que 36.3\% dos brasileiros entrevistados responderam que compram para aliviar o estresse cotidiano e os jovens são os que mais realizam compras por impulso, representando $41,8 \%$ do total. A pesquisa também revela que 30.1\% se arrependem de terem gastado mais do que o desejado com as compras não planejadas, e outros $25.8 \%$ revelaram que não analisam todas as variáveis que envolvem a compra.

Os dados nacionais reforçam o que a pesquisa com o grupo de estudantes do EJA mostrou, que uma boa parte realiza compras por impulso e que depois se arrepende de tê-las feito. A tabela 5 apresenta esses dados.

\section{Tabela 05 - Compra por impulso}

\begin{tabular}{|c|c|c|}
\hline Possibilidades & Frequência & Porcentagem \\
\hline Achou um produto melhor ou mais em conta depois & 05 & 10,0 \\
\hline Não precisava tanto & 07 & 14,0 \\
\hline Nunca comprei nada impulsivamente & 17 & 34,0 \\
\hline $\begin{array}{c}\text { O Objeto não deixou você tão feliz quanto pensava que } \\
\text { deixaria }\end{array}$ & 05 & 10,0 \\
\hline $\begin{array}{c}\text { Percebeu que o objeto não era de boa qualidade ou } \\
\text { durou pouco }\end{array}$ & 03 & 6,0 \\
\hline Precisou do dinheiro para outra coisa depois & 12 & 24,0 \\
\hline Optou não responder & 01 & 2,0 \\
\hline Total & 50 & 100,0 \\
\hline
\end{tabular}

Fonte: Elaborada pelos autores.

Os entrevistados mostram-se mais adeptos ao pagamento à vista, em que 58\% disseram preferir pagar logo suas compras e não acumular dívidas, enquanto outros $42 \%$ preferem utilizar o cartão de crédito e parcelar; portanto, foi perguntado a eles se possuíam ou utilizavam cartão de crédito: 44\% responderam não ter cartão de crédito; 36\% têm; e outros 20\% utilizam de algum parente, alguns por já estarem inadimplentes, outros por não quererem fazer um próprio. Dos participantes que declaram ter cartão de crédito, 50\% têm apenas um, 33,3\% têm dois e 16,7\% possuem mais de três cartões.

Em 2018, os dados do SPC, o Banco Central do Brasil (BCB) mostraram que $41 \%$ dos brasileiros preferem sempre pagar à vista (especialmente as classes $\mathrm{C} / \mathrm{D} / \mathrm{E}$ ) e $34 \%$ optam pelo pagamento à vista, se o desconto for vantajoso 
(principalmente as classes A/B) e ainda mostram que quando o consumidor quer parcelar, o meio preferido é o cartão de crédito (66\%). Mostrando que o perfil apresentado pelos entrevistados apresenta estar de acordo com os da mesma classe social nas demais regiões do país.

Depois de saber a preferência de pagamentos dos estudantes, foi perguntado se eles estão ou já estiveram inadimplentes alguma vez na vida. Dos 50 estudantes, $40 \%$ encontram-se na lista do Serasa, 22\% conseguiram sair e 34\% nunca estiveram inadimplentes. Segundo Rocha; Oliveira e Teixeira (2017) houve uma redução, nos últimos anos, da inadimplência dos consumidores de baixa renda, tal resultado pode ser reflexo do processo de educação financeira. Porém, essa redução não foi sentida na amostra analisada.

Através do gráfico 1 pode ser observado o tempo de inadimplência dos entrevistados, o qual mostra que $47,4 \%$ estão inadimplentes há pouco tempo, entre 1 a 4 meses; e 26,3\% estão inadimplentes há mais de dois anos, sem conseguir pagar suas dívidas.

\section{Gráfico 01 - Tempo de inadimplência}

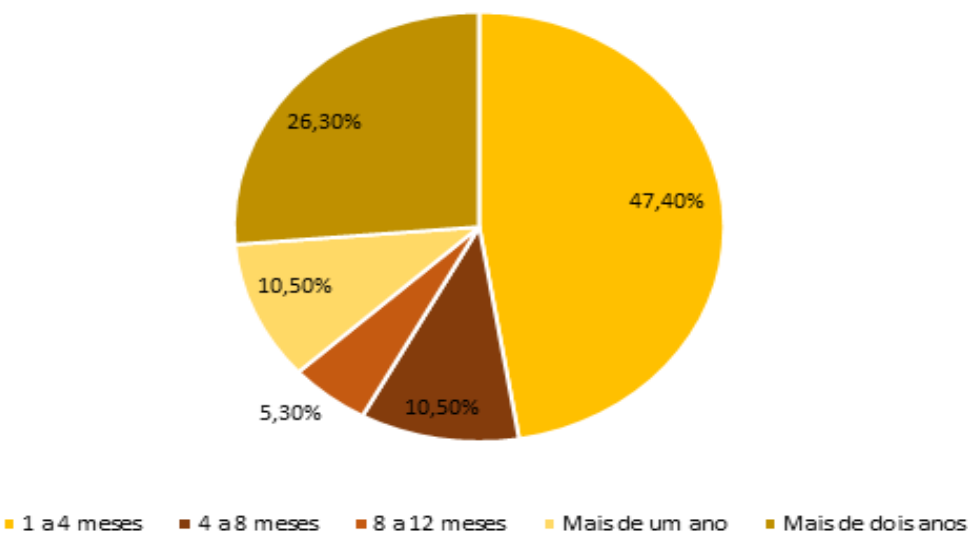

Fonte: Elaborada pelos autores.

Quando perguntados se eles têm algum familiar inadimplente, 50\% responderam que sim, 22\% relataram que tiveram parente endividado, mas conseguiram pagar suas dívidas, outros $22 \%$ disseram que não tinha ninguém da família com dívidas e 6\% não sabiam essa informação. Para Rocha; Oliveira 
e Teixeira (2017), o crédito pode ser apontado como o principal incentivador do consumo, aliada à falta de educação financeira e a outros aspectos comportamentais, isso contribui para o aumento da inadimplência.

Isso mostra que o grupo entrevistado possui dificuldade para se livrar das dívidas, comprometendo grande parte de sua renda. Por meio deste segundo gráfico pode ser observado o tempo de inadimplência dos familiares que estão na lista do Serasa, em que 24\% estão há pouco tempo, de 1 a 4 meses, e $12 \%$ estão há mais de dois anos tentando quitar seus débitos.

\section{Gráfico 02 - Tempo de inadimplência dos familiares}

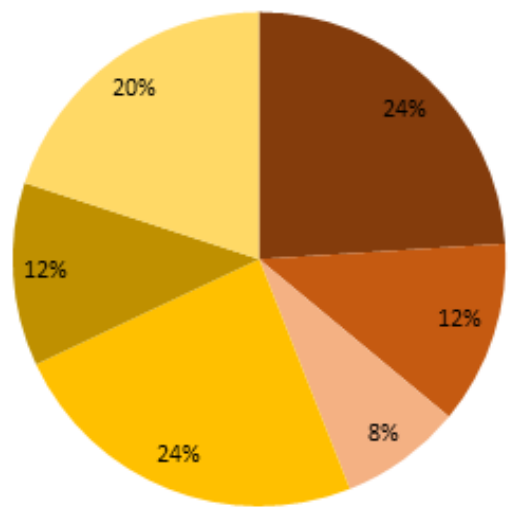

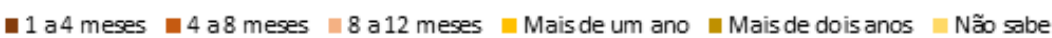

Fonte: Elaborada pelos autores.

Conforme o SERASA (2019), a parcela da população adulta inadimplente chega a 40.6\% em todo o país. Em Alagoas, esse percentual é de 37.9\%, representando $1,4 \%$ dos inadimplentes do Brasil. É possível perceber que os adultos entre 36 e 40 anos representam a faixa de maior inadimplência, além deles, $31.2 \%$ dos jovens entre 18 e 25 anos estão inadimplentes.

O total de inadimplentes no país reflete a realidade local de pessoas que deixam de pagar suas contas, podendo ser visto na tabela 06. E que tais dados estão em consonância com a amostra apresentada neste estudo. Para Macedo Jr (2007), a dificuldade do brasileiro em administrar seu orçamento, dívidas e adquirir bens, contribui para a inadimplência e o endividamento. 


\section{Tabela 06 - Inadimplentes por faixa etária}

\begin{tabular}{|c|c|}
\hline Faixa de idade & \% inadimplentes por idade \\
\hline 18 a 25 & 31.2 \\
\hline 26 a 30 & 44.6 \\
\hline 31 a 35 & 46.4 \\
\hline 36 a 40 & 48.4 \\
\hline 41 a 50 & 45 \\
\hline 51 a 60 & 38.9 \\
\hline +61 & 35.5 \\
\hline TOTAL & 40.6 \\
\hline
\end{tabular}

Fonte: Serasa Experian, 2019.

O perfil dos entrevistados revela um comportamento de um público de baixa renda e com grande parte desta comprometida para pagamento de despesas básicas e dívidas. Silva (2004) afirma que os brasileiros não foram educados para pensar sobre o dinheiro na forma de gestão e, assim, a maioria gasta aleatoriamente sem refletir sobre a sua renda e seus impactos a longo prazo. Isso mostra que iniciativas como as oficinas do projeto podem impactar positivamente os presentes.

\section{CONHECIMENTOS EM FINANÇAS}

Após conhecer o perfil de consumo do grupo de entrevistados, foi mensurado o nível de conhecimento a respeito de orçamento financeiro, em que pôde ser percebido que 34\% têm algum conhecimento a respeito, enquanto 30\% não o têm, $8 \%$ têm alguma noção sobre o assunto, 24\% ficaram em dúvida e 4\% optaram por não responder.

Para Peter e Palmeira (2013), a ausência de educação financeira acaba por estimular os agentes a fazerem escolhas erradas que levam a comprometer grande parte de sua renda. Esta ausência de conhecimento pode explicar, em parte, os dados da situação financeira e inadimplência dos entrevistados.

Depois dessa pergunta introdutória foi questionado aos entrevistados como eles consideravam a situação financeira atual, $44 \%$ declararam que suas finanças estão controladas, $32 \%$ disseram que estão um pouco desorganizadas com algumas dívidas para pagar, $12 \%$ consideram que suas finanças estão desorganizadas, não tendo controle no que gastam, com muitas dívidas acumuladas e $12 \%$ optaram por não responder este questionamento, como pode ser visualizado na tabela 7 . 


\section{Tabela 07 - Situação financeira dos participantes}

\begin{tabular}{|c|c|c|}
\hline Possibilidades & Frequência & Porcentagem \\
\hline $\begin{array}{c}\text { Desorganizada. Não sei quanto gasto, nem quanto devo ao certo, tenho muitas } \\
\text { dívidas e não estou conseguindo pagar. }\end{array}$ & 06 & 12,0 \\
\hline $\begin{array}{c}\text { Organizada. Tenho controle sobre meu dinheiro, não tenho dívidas que } \\
\text { comprometem meu orçamento e poupo sempre que possível. }\end{array}$ & 22 & 44,0 \\
\hline $\begin{array}{c}\text { Um pouco desorganizada. Não sei exatamente quanto gasto por mês, tenho } \\
\text { algumas dividas que consigo pagar, mas não consigo poupar. }\end{array}$ & 16 & 32,0 \\
\hline Optou por não responder & 06 & 12,0 \\
\hline Total & 50 & 100,0 \\
\hline
\end{tabular}

Fonte: Elaborada pelos autores.

Com uma boa parcela de entrevistados desorganizados no quesito financeiro, foi perguntado então se eles acham importante o tema educação financeira, que seria o tema central das oficinas que seriam ministradas, assim pôde ser analisado o nível de interesse sobre a temática. Dos entrevistados, $90 \%$ disseram achar importante o tema, enquanto $6 \%$ não consideram essencial, $4 \%$ optaram por não responder. Perguntados se já tiveram algum tipo de capacitação com o tema, $66 \%$ revelaram-se leigos sobre o assunto, $14 \%$ já estudaram algo a respeito e $6 \%$ se abstiveram de responder.

Para Willis (2009) a educação financeira é essencial para fundamentar e legitimar a tomada de decisão relativa a assuntos financeiros. Mesmo com o desconhecimento financeiro apresentado, o grau de interesse dos presentes foi alto, mostrando que o público em questão acredita que o conteúdo das oficinas pode contribuir para aprimorar a gestão das finanças pessoais.

Segundo Cordeiro, Almeida, e Figueiredo (2013), os agentes educados financeiramente alteram sua percepção em relação às suas despesas e receitas, logo, podem repensar seus gastos e reduzir o endividamento. Entretanto, os dados aqui apresentados confirmam os estudos de Silva (2004); Leal e Melo (2008) e; Rocha; Oliveira e Teixeira (2017) que mostram que os indivíduos continuam tendo baixo nível de educação financeira.

Para entender melhor o público que participaria das oficinas foi questionado quem é na casa deles o responsável por cuidar do dinheiro e controlar os gastos domésticos. A maioria (62\%) disse que eles mesmos cuidam de tudo, já $26 \%$ delegam essa responsabilidade para seus pais, $8 \%$ repassam para um terceiro, sendo geralmente o cônjuge e 4\% não quiseram revelar essa informação.

Já sabendo quem cuida do dinheiro que entra mensalmente para os gastos domésticos e pessoais, foi perguntado como esse dinheiro é administrado, $60 \%$ não souberam responder esse questionamento, $22 \%$ gostam de anotar em um caderno ou agenda cada conta que precisa ser paga, $10 \%$ administram por ordem 
de prioridade, pagando primeiramente as contas de água e luz para então pagar as contas pessoais e $8 \%$ revelaram que não administram bem seus gastos.

O consumidor de baixa renda possui uma quantidade de despesas básicas que extrapolam suas capacidades financeiras, tal fato compromete sua subsistência e, por isso, resulta em inadimplência, pois acaba priorizando as contas de primeira necessidade (NOGAMI, VIEIRA, \& MEDEIROS, 2012; ROCHA; OLIVEIRA E TEIXEIRA, 2017).

Quem deseja comprar algo de um valor considerado alto ou quer se livrar das dívidas acumuladas precisa adquirir um hábito considerado primordial, o hábito de poupar. Levando isso em consideração, 40\% dos entrevistados revelaram que às vezes poupam, mas não sempre; $30 \%$ não guardam nada; $22 \%$ dizem que têm esse hábito e todo dinheiro que acaba sobrando no final do mês é guardado; e $8 \%$ optaram por não responder a esse questionamento.

Para que isso seja viável, eles não devem comprometer sua renda com dívidas, planejar o uso da renda, tendo como finalidade a criação de metas e delinear quais serão os esforços necessários para alcançá-las (CORDEIRO; ALMEIDA; FIGUEIREDO, 2013; LEVINO; DOS SANTOS, 2019).

\section{EXPECTATIVAS}

Para verificar o real interesse das turmas foi perguntado se os entrevistados consideram importantes as oficinas que seriam ministradas com conteúdo de educação financeira, e ajudá-los a cuidar melhor do seu dinheiro e administrar seus gastos. Eles responderam o seguinte: 70\% acharam que seria importante para seu processo de formação, $12 \%$ disseram que talvez sim, $12 \%$ consideraram desinteressante e $6 \%$ preferiram não se manifestar.

Por fim, finalizando esse questionário, foi deixado um espaço para eles responderem livremente o que eles esperavam que iria melhorar em sua vida com os conhecimentos que seriam transmitidos através das oficinas. Muitas respostas foram similares, sendo a mais comum o fato de aprender a economizar $(26 \%)$, seguido pelo fato de adquirir novos conhecimentos $(22 \%)$, porém, a maioria $(46 \%)$ não sabiam ainda o que iria ser agregado. Das respostas dadas pelos participantes vale destacar três respostas que demonstram a vontade pelo aprendizado e como a educação financeira iria impactar sua vida:

- "Poderei aprender a ter uma visão melhor dos meus gastos, aprender a controlá-los e saber como poupar meu dinheiro mensalmente";

- "A qualidade de vida, vai melhorar o meu emocional, pois fico até sem dormir, preocupado"; 
- "Para que eu tenha um conhecimento a mais, como eu devo ser mais administrativo e econômico".

Com o perfil dos participantes identificados foram realizados alguns ajustes nas oficinas: Matemática no cotidiano, Planejamento Financeiro e Gestão de Custos Pessoais. As mudanças foram necessárias para alinhar as necessidades apresentadas no comportamento anteriormente descrito e torná-las mais atrativas para o público.

Buscou-se realizar oficinas mais práticas, nas quais o conteúdo era apresentado através de exemplos cotidianos e dinâmicas eram realizadas ao final de cada exposição. A participação dos presentes foi estimulada, de modo que fosse vislumbrado como o conteúdo poderia contribuir no seu dia a dia.

Após a última oficina foi aplicado um segundo questionário ${ }^{1}$ para saber a percepção dos estudantes sobre o projeto de extensão e das oficinas. Sendo apresentado o seguinte resultado a respeito do nível de participação: 24,4\% dos alunos se fizeram presentes em todas as oficinas, $26,8 \%$ participaram de três; a mesma porcentagem de duas oficinas; e 22\% apenas de uma.

Vale ressaltar que os alunos não receberam bonificação para participar das oficinas e que sua participação ocorria de forma voluntária, e que alguns professores estimulavam se fazendo presentes durante o processo. Dado tal fato, considera-se que a participação dos estudantes ocorreu de modo regular.

Perguntados pelo tema que mais agradou, sendo possível marcar mais de uma opção, 42,5\% gostaram da terceira oficina que levou como tema planejamento financeiro; $27,5 \%$ da última que falou sobre a gestão de custos pessoais; $25 \%$ se dividiram igualmente entre a primeira e segunda oficina que tiveram como assuntos qual o seu sonho? e matemática no cotidiano, respectivamente; $17,5 \%$ gostaram de todos os temas abordados; e 7,5\% de nenhum.

Como forma de saber como eles consideravam o próprio nível de conhecimentos findadas as oficinas, 53,7\% consideraram estar com nível bom, $22 \%$ consideraram excelente, $19,5 \%$ como regular e $4,9 \%$ como ruim.

Perguntado o que tinham aprendido com as oficinas, a resposta mais comum que pôde ser avaliada foi: economizar. Apesar de 07 pessoas não terem conseguido elaborar uma resposta, outras acabaram chamando a atenção e serão apresentadas a seguir:

- "A economizar todos os meses, para no futuro comprar algo necessário";

- "A economizar, se planejar, evitar gastos desnecessários para conseguir realizar meus sonhos";

- "Planejar de acordo com minha renda mensal";

1 Alguns alunos não foram para a escola no dia da última oficina, reduzindo o número de 50 respondentes do primeiro questionário - para 41 no segundo. 
- "Pesquisar mais, a sempre pechinchar e economizar";

- "Aprendi a economizar, não gastar sem precisão, ajudar mais dentro de casa e gastar com coisas que realmente importam";

- "Aprendi a planejar e como utilizar a matemática no meu dia a dia";

- "A dar valor ao dinheiro, cada suor vale centavo".

As respostas finais e o interesse dos estudantes durante este ciclo mostraram como as oficinas foram importantes e agregadoras, exatamente como Famá e Prado (2016) evidenciam, mostrando que a educação financeira é um dos conhecimentos necessários para as pessoas conviverem em sociedade.

\section{CONSIDERAÇÕES FINAIS}

Ao fim do projeto de extensão e, após todo o processo de pesquisa e aplicação das oficinas, foi percebida a lacuna que é deixada pela educação financeira na vida cotidiana das pessoas. A pesquisa apontou que há falta de conhecimento e controle financeiro dos estudantes, tornando assim adultos descontrolados financeiramente e sem conhecimentos básicos de como administrar seu dinheiro.

As oficinas foram o principal instrumento utilizado para difundir o conhecimento sobre os temas abordados, de uma maneira prática, dinâmica e interativa. Os alunos puderam ter contato com conceitos que até então, eram desconhecidos para a maioria. Com isso, espera-se que haja uma melhora sobre os hábitos financeiros dos participantes.

O interesse demonstrado pelo assunto, o perfil dos entrevistados e avaliação do aprendizado demonstram a necessidade de projetos nessa temática junto à comunidade. Os relatos dos estudantes que participaram das oficinas e durante a execução delas mostraram como esse tipo de conhecimento fará diferença em suas vidas, principalmente em regiões de maior vulnerabilidade isso se faz necessário.

A equipe envolvida nas ações pôde, por meio da troca de experiências, absorver e aperfeiçoar seu entendimento em finanças pessoais, contribuindo assim para a expansão do conhecimento além da sala de aula.

As limitações foram diversas, desde troca de direção da escola, horários incompatíveis, conhecimento de alguns termos técnicos e outros problemas externos. Todas essas questões devem ser pontuadas e, com isso, entende-se que, no processo de ensino, fatores sociais são de extrema relevância. 
Como sugestão de trabalhos futuros indica-se a expansão do campo de pesquisa, com uma amostragem mais ampla, comparando comportamentos de diferentes escolas, de bairros e/ou com pessoas que não conseguiram concluir a educação básica, buscando entender às necessidades dessa população em específico, para assim buscar soluções adequadas.

\section{REFERÊNCIAS}

AMARAL JUNIOR, José Carlos do. (2013). Educação para mulheres: análise histórica dos ensinamentos de economia doméstica no Brasil. Revista HISTEDBR On-Line, 13(52), 275-285.

ARAÚJO, Fabio de Almeida Lopes; SOUZA, Marcos Aguerri Pimenta de. Educação Financeira para um Brasil Sustentável Evidências da necessidade de atuação do Banco Central do Brasil em educação financeira para o cumprimento de sua missão. Disponível em: https://www.bcb.gov.br/pec/ wps/port/TD280.pdf. Acesso em: 20 set. 2019.

BANCO CENTRAL DO BRASIL (BCB). Uso Do Crédito - O Que Diz O Consumidor. Disponível em: https://www.bcb.gov.br/nor/relcidfin/docs/ art5_uso_do_credito.pdf. Acesso em: 10 nov. 2019.

BRUTES, Larissa; SEIBERT, Rosane Maria. O ensino da educação financeira a jovens de escolas públicas de Santo Ângelo. Vivências. Vol. 10, N.18: p. 174-184, Maio/2014

CARVALHO, Cicero Péricles de. Economia popular: uma via de modernização para Alagoas. 7 ed. Maceió: Edufal, 2016.

CORDEIRO, Rafaela Almeida; ALMEIDA, Liliane. Matias de; FIGUEIREDO, J. C. (2013). Classe média brasileira: Mais dinheiro e menos dívidas, sonho ou realidade?. In: Anais IV Encontro de Administração Política para o desenvolvimento do Brasil. Salvador: UFBA.

DORNELA, Fernanda Junia; TEIXEIRA, Fábio André; COSTA, Ricardo Freitas Martins da; SANTOS JÚNIOR, Walter Luiz dos; SOUZA, Luíza Mendes. Educação Financeira: aprendendo a lidar com o dinheiro. Raízes e Rumo, VOL. $02 \mathrm{~N}^{\circ}$ 01, 91 - 155, Rio de Janeiro, Jun., 2014. 
FAMÁ, Rubens; PRADO, André Brisola Brito. O consumo e a importância da Educação Financeira para o Brasil. ReFAE - Revista da Faculdade de Administração e Economia, v. 8, n. 1, p. 02-12, 2016.

FECOMERCIO. Pesquisa de Endividamento e Inadimplência do Consumidor. Disponível em:http://www.fecomercio-al.com.br/instituto/wpcontent/uploads/sites/2/2019/11/PEICoutubro2019.pdf. Acesso em: 10 nov. 2019.

GITMAN, Lawrence Jeffrey. Princípios de administração financeira. 10 ed. São Paulo: Pearson Addison Wesley, 2004.

GOVERNO DE ALAGOAS (2019). Ações sociais e culturais do Ronda no Bairro movimentam o Jacintinho. Agência Alagoas, Maceió. Disponível em: http:// www.agenciaalagoas.al.gov.br/noticia/item/29088-acoes-sociais-e-culturais-doronda-no-bairro-movimentam-o-jacintinho. Acesso em: 12 nov. 2019.

GUEDES, Terezinha Aparecida; et al. Estatística Descritiva. Disponível em: http://www.each.usp.br/rvicente/Guedes_etal_Estatistica_Descritiva.pdf. Acesso em: 10 nov. 2019.

HEMAIS, Marcos Wilcox; CASOTTI, Letícia Moreira; ROCHA, Everaldo Pereira Guimarães. (2013). Hedonismo e moralismo: Consumo na base da pirâmide. Revista de Administração de Empresas, 53(2), 199-207.

IBGE. Habitação. Disponível em: https://brasilemsintese.ibge.gov.br/ habitacao.html. Acesso em: 10 dez. 2019.

IBGE. Condição de habitação. Disponível em: https://brasilemsintese.ibge. gov.br/habitacao/condicao-de-ocupacao.html. Acesso em: 10 dez. 2019.

IBGE. Pesquisa Nacional por Amostra de Domicílios - PNAD. Disponível em: https://www.ibge.gov.br/estatisticas/sociais/habitacao/9127-pesquisanacional-por-amostra-de-domicilios.html? $=\& \mathrm{t}=$ destaques. Acesso em: $10 \mathrm{dez}$. 2019.

LEAL, Douglas Tavares Borges; MELO, Sheila De. (2008). A contribuição da educação financeira para a formação de investidores. Seminários em Administração. São Paulo: USP. 
LEVINO, Natallya de Almeida; DOS SANTOS, Anderson Moreira Aristides (ORG). Finanças Pessoais para iniciantes. Maceió: Edufal, 2019.

MACÊDO, Sarah Martins de. A Importância Da Educação Financeira Nas Escolas Na Perspectiva Do Consumo Infantil. 2016. Trabalho de Conclusão de Curso (Bacharelado em Economia.) - UNIVERSIDADE FEDERAL RURAL DE PERNAMBUCO, Recife, 2016. Disponível em: < http://www. educacaofinanceira.com.br/tcc/sarahmacedo.pdf>. Acesso em: 30 jan. 2019.

MACEDO Jr., Jurandir Sell. (2007). A árvore do dinheiro: Guia para cultivar a sua independência financeira. Rio de Janeiro: Elsevier.

MATTOOSO, Cecilia Queirós; ROCHA, Ângela Da. (2005). Significados associados às estratégias para solução de problemas financeiros dos consumidores pobres. Encontro da Associação Nacional de Pós-graduação e Pesquisa em Administração. Rio de Janeiro: ANPAD.

MENDONÇA, Vivianne da Silva; MELO, Maria de Fátima Massena. Economia familiar, consumo e orçamento doméstico. In: Anais XX Congresso Brasileiro de Economia Doméstica. Fortaleza/CE. Disponível em: http://www.xxcbed.ufc. br/arqs/gt5/gt5_07.pdf. Acesso em: 25 set. 2019.

MINISTÉRIO DA CIDADANIA. Bolsa Família atende mais de 13,5 milhões de beneficiários em setembro. Disponível em: http://mds.gov.br/area-deimprensa/noticias/2019/setembro/bolsa-familia-atende-mais-de-13-5-milhoesde-beneficiarios-em-setembro. Acesso em: 10 dez. 2019.

NARDI, Sérgio. (2009). A nova era do consumo de baixa renda: Consumidor, mercados, tendências e crise mundial. São Paulo: Novo Século Editora.

NEALDO, Carlos. Alagoas tem a segunda maior taxa de desalentados do País, apontam dados do IBGE. Gazeta Web. Alagoas, 2019. Disponível em: https:/ / gazetaweb.globo.com/portal/noticia/2019/11/_90959.php. Acesso em: 10 dez. 2019.

NOGAMI, Vitor Koki; VIEIRA, Francisco Giovanni; MEDEIROS, Juliana. (2012). Reflexões acadêmicas e de mercado para o marketing na base da pirâmide. Revista de Negócios, 17(4), 55-73. 
OLIVEIRA, Ana Carla Menezes de. Economia doméstica: origem, desenvolvimento e campo de atuação profissional. Vértices, v. 8, n. 1/3, jan./ dez. 2006.

OLIVEIRA, Anessandra Eliza de; MACHADO, Flávia Fernanda da Silva; MARTINS, Júlio Cesar; SPOSITO. R. R. A importância da educação financeira no contexto escolar e familiar: uma amostra do projeto implantado na UNESPAR. 2014. Disponível em: < https://bit.ly/2QBomCD >. Acesso em 20 de mar de 2019.

PADOVEZE, Clóvis Luís. Introdução à administração financeira. São Paulo: Pioneira Thomson Learning, 2005.

PETER, Luciani. Dallmann.; PALMEIRA, Eduardo. Mauch. Estudo sobre a inclusão da educação financeira como disciplina escolar a partir das séries iniciais. Cuadernos de Educación y Desarrollo, Servicios Académicos Intercontinentales, issue 33, 2013. Disponível em <https://ideas.repec.org/a/ erv/cedced/y2013i3310.html > Acesso em 10 de fev. de 2019.

PICCINI, Ruberlan Alex Bilha; PINZETTA, Gilberto. Planejamento Financeiro Pessoal e Familiar. Unoesc \& Ciência - ACSA, Joaçaba, v. 5, n. 1, p. 95-102, jan./ jun. 2014.

QUINTANA, Alexandre Costa; PACHECO, Katiani Velleda. Percepção dos estudantes do ensino fundamental sobre educação financeira e consumo consciente. Revista Educação Online, Rio de Janeiro, n. 27, jan-abr 2018, p. 130-150.

RIBEIRO, Caroline do Amaral; VIERA, Kelmara Mendes; SANTOS, João Heitor de Avila; TRINDADE, Larissa de Lima; MALLMANN, Estela Isabel. Finanças Pessoais: análise dos gastos e da propensão ao endividamento em estudantes de administração. In: Anais Seminários em Administração. São Paulo/SP Disponível em: http://sistema.semead.com.br/12semead/resultado/ trabalhosPDF/385.pdf. Acesso em: 02 out. 2019.

RIOS, Dermival Ribeiro. Minidicionário escolar da língua portuguesa. São Paulo: DCL, 2009. 
ROCHA, Rodrigo Ribeiro; OLIVEIRA, Ronielton Rezende; TEIXEIRA, Luiz Antônio Antunes. Educação financeira e endividamento do consumidor de baixa renda: Tendências de inadimplência e adimplência. In: Congresso de Administração, Sociedade e Inovação. Petropólis/RJ, 2017.

SANTOS, Adla Carla; SILVA, Maciel. Importância do Planejamento Financeiro no Processo de Controle do Endividamento Familiar: Um Estudo de Caso nas Regiões Metropolitanas da Bahia e Sergipe. Revista Formadores: Vivências e Estudos, Cachoeira-BA, v. 7 n. 1, p. 05-17, Jun. 2014.

SAVOIA, José Roberto Ferreira; SAITO, André Taue; SANTANA, Flávia de Angelis. Paradigmas da educação financeira no Brasil. Revista de Administração Pública (RAP), Rio de Janeiro 41(6):1121-41, Nov./Dez. 2007.

SERASA. O que é inadimplência e como ela afeta sua vida? Disponível em: https://www.serasaconsumidor.com.br/ensina/seu-nome-limpo/o-que-einadimplencia/. Acesso em: 20 set. 2019.

SERASA. Um em cada cinco inadimplentes no Brasil tem entre 41 e 50 anos, revela Serasa Experian. Disponível em: https://www.serasaexperian.com.br/ sala-de-imprensa/um-em-cada-cinco-inadimplentes-no-brasil-tem-entre-41-e50-anos-revela-serasa-experian. Acesso em: 10 nov. 2019.

SILVA, Amalrido Melchiades; POWELL, Arthur Belford. Um programa de Educação Financeira para a matemática escolar da Educação Básica. In: Anais Encontro Nacional de Educação Matemática. Curitiba/PR, 2013. Disponível em: http://sbem.iuri0094.hospedagemdesites.ws/anais/XIENEM/ pdf/2675_2166_ID.pdf. Acesso em: 25 set. 2019.

SILVA, Sandra Luiza Moraes; BEZERRA, Renata Camacho. A Educação Financeira como proposta para uma vida economicamente equilibrada. Cadernos PDE, Versão Online. ISBN: 978-85-8015-093-3. Disponível em: http:/ / www.diaadiaeducacao.pr.gov.br/portals/cadernospde/pdebusca/producoes_ pde/2016/2016_artigo_mat_unioeste_sandraluizamoraessilva.pdf. Acesso em: 25 set. 2019.

SILVA, Eduardo. D. (2004). Gestão em finanças pessoais: Uma metodologia para se adquirir educação e saúde financeira. Rio de Janeiro: Quatymark. 
SILVA, Gildo (2014). Jacintinho é um dos bairros mais violentos da capital. Gazeta de Alagoas. Disponível em: http://gazetaweb.globo.com/gazetadealagoas/ noticia.php?c $=246451$. Acesso em: 20 nov. 2019.

SPC BRASIL. 36\% dos consumidores fazem compras para aliviar o estresse, aponta pesquisa do SPC Brasil. Disponível em: https://www.spcbrasil.org.br/ pesquisas/pesquisa/1207. Acesso em: 02 out. 2019.

TEIXEIRA, James. Um estudo diagnóstico sobre a percepção da relação entre educação financeira e matemática financeira. 2015. Tese (Doutorado em Educação Matemática) - Faculdade de Educação, Pontífica Universidade Católica de São Paul, São Paulo, 2015. Disponível em: https://tede.pucsp.br/ handle/handle/11025. Acesso em: 10 dez. 2019.

VIEIRA, Saulo Fabiano Amancio; BATAGLIA, Regiane Tardiolle Manfre; SEREIA, Vanderlei José. Educação Financeira e Decisões de Consumo, Investimento e Poupança: uma análise dos alunos de uma Universidade Pública do Norte do Paraná. Revista de Administração da UNIMEP - v.9, n.3, Setembro / Dezembro - 2011. Página 61 -86.

WILIIS, Lauren. E. (2009). Evidence and ideology in assessing the effectiveness of financial literacy education. San Diego Law Review, 46(1), 415-447.

ZERO, Arethuza Helena. Educação Financeira estará no currículo das escolas até 2020. Educa Financeira, 2019. Disponível em: https://www.educafinanceira. com.br/educacao-financeira-estara-no-curriculo-das-escolas-ate-2020/. Acesso em: 23 set. 2019. 


\section{Rerisson Kaique de Oliveira Valentim}

Bacharel em Administração pela Universidade Federal de Alagoas. E-mail: rerisson.kaique@gmail.com

\section{Kelly Christian dos Santos Rodrigues}

Graduanda em Administração pela Universidade Federal de Alagoas. E-mail: kellyrodrigues@outlook.com

\section{Natallya de Almeida Levino}

Doutora em Engenharia da Produção e Professora da Faculdade de Economia, Administração e Contabilidade - FEAC/Universidade Federal de Alagoas UFAL. E-mail: natallya.levino@feac.ufal.br

Recebido em 06/02/2020

Aprovado em 31/07/2020 